\title{
INTEGRATION OF GIS TECHNOLOGY FOR FUZZY - DETERMINISTIC MODELING CONDITIONS OF FORMATION AND OPERATION KEGEYLI GROUNDWATER IS ABSTRACTED
}

\author{
Seitnazarov Kuanyshbaev Kenesbaevich ${ }^{1}$ \\ ${ }^{I}$ Tashkent University of Information Technologies, Tashkent, Uzbekistan
}

\begin{abstract}
Offers scientific and methodological basics for application of fuzzy-deterministic simulation geofiltration processes in single layers on the basis of the application of GIS technology in terms of dominance fuzzy initial information. GIS model of Kegeyli withdrawal of groundwater (KWGV) is carried out on the basis of software including ArcGIS (ArcCatalog, ArcMap). The problems of a situational analysis of the results clearly-deterministic simulation. The proposed information model and information model KWGV filtration process to ensure that the relationship between the object model and the geofiltration, represented as a system of fuzzy-deterministic two-dimensional (quasi three-dimensional) nonlinear differential equations filtering and organizing computational experiments (CE). In this context, discusses aspects of geoinformation approach in the process of fuzzy-deterministic simulation of operating conditions Kegeyli abstraction of groundwater. It is proposed software system that focuses on the study of hydro geological objects, both local and regional scale using data from heterogeneous. Formalization of fuzzy algorithms parameters of underground hydrosphere, the relationship abstraction of groundwater and its model. The algorithms select the solution in the formation and exploitation of groundwater resources, the principles of the information model of the region of the filtering process. The results of solving the problem of formalization of parameters and forecast the state of groundwater Kegeyli withdrawals of groundwater.
\end{abstract}

Keywords: groundwater intakes, fuzzy-deterministic approach, the computational process, information model, geofiltration, information models, symbolic model GIS.

\section{INTRODUCTION}

The problem of drinking water in the areas of environmental stress remains very topical issue. Deterioration of water quality of surface runoff negative impact on the stability of lenses of fresh groundwater.

In a large part of the previously explored areas lenses of fresh groundwater was increased salinity of groundwater, which impairs their quality. Although riparian and near the chanel lenses of fresh groundwater are still one of the main sources of centralized economic - drinking water supply.

Currently, the most Poorly supplied with water from groundwater is the territory of the left bank of Kegeyli district.

Mathematical modeling and numerical simulation (NS) is one of the important ways to obtain new information about the study of hydrogeological objects (HGO). However, for most HGO are typical strengthening the influence of anthropogenic factors on them, which are the causes of unreliability of data, the measurement parameters of the environment, etc. Uncertainty, ambiguity, indeterminacy, unpredictable behavior characteristics of HGO and their parameters is explained by the need to integrate the modeling problem solving and decision-making within a single computer system. In this context, this article discusses aspects of geoinformation approach in the process of fuzzy- deterministic simulation conditions of functioning Kegeyli withdrawals of groundwater (KWGV).

\section{HYDROGEOLOGICAL CONDITIONS OF THE TERRITORY}

Geologically, the site is composed of Quaternary alluvial deposits, which are underlain by sandstones of Neogene age. Water-bearing rocks are fine-grained sands of Quaternary age. At a depth of $12-17.0 \mathrm{~m}$. lies a layer of loam, which has not widespread distribution.

According to the results of exploration in 1961-62, fresh groundwater reserves in the area approved by the author's version for industrial categories: A-2.50 thousand $\mathrm{m}^{3} /$ day, B-2.80 thousand $\mathrm{m}^{3} /$ day, C-15 thousand $\mathrm{m}^{3} /$ day. In 199093 revalued operational stocks of fresh groundwater sites in the context of artificial replenishment of stocks. Balance reserves on a site approved by the Scientific and Technical Council "Uzbekhydrogeology" on August 1, 1988.

Technological scheme of artificial formation and artificial fill reserves of fresh groundwater (RFG) consists of water intake, located at a distance $\mathrm{L}_{1}$ from the irrigation canal (IC) and at a distance $\mathrm{L}_{2}$ from the flow channel, parallel water intake that allows to carry out artificial formation and artificial fill reserves of fresh groundwater [11,12]. The technological scheme is shown on the fig. 1. 


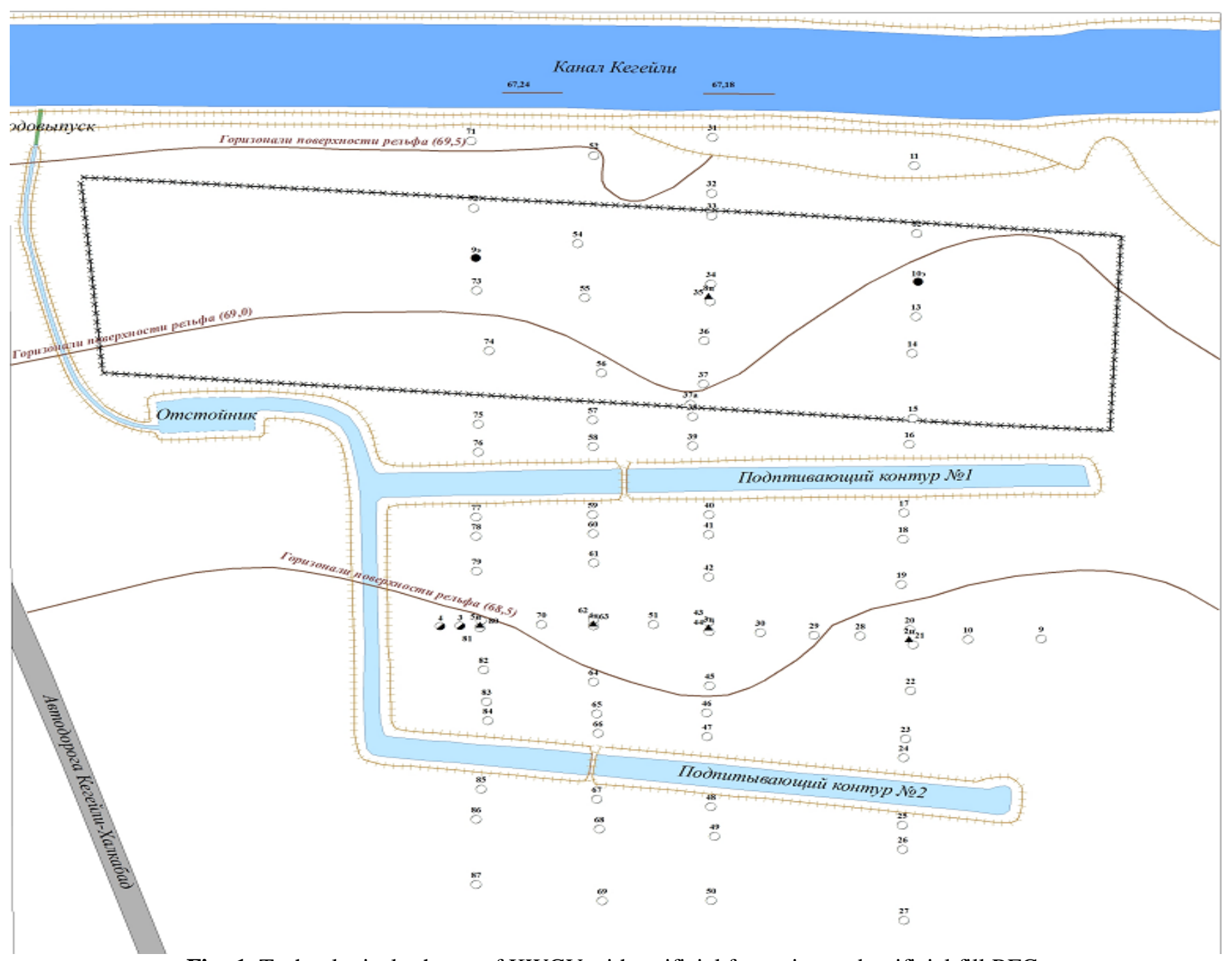

Fig -1: Technological scheme of KWGV with artificial formation and artificial fill RFG.

\section{FUZZY-DETERMINISTIC MODEL OF KWGV}

Mathematical modeling of processes for geofiltration hydrogeological objects of natural manmade carried out on the basis of fuzzy-deterministic model geofiltration that for a single-layer structure of the aquifer has the following form $[4,5,6]$ :

$$
\begin{aligned}
& \mu \frac{\partial h}{\partial t}=\frac{\partial}{\partial x}\left(\tilde{k} h \frac{\partial h}{\partial x}\right)+\frac{\partial}{\partial y}\left(\tilde{k} h \frac{\partial h}{\partial y}\right)+f-w \\
& h(x, y, 0)=\tilde{h}_{0}(x, y),(x, y) \in D \\
& \alpha h(x, y, t)+\left.\beta\left(\tilde{k} h \frac{\partial h}{\partial n}\right)\right|_{(x, y) \in \Gamma}=\tilde{\gamma}(x, y, t)
\end{aligned}
$$

Here $\mu$ - the coefficient of water loss (lack of saturation); $h(x, y, t), \quad f(x, y, t), \quad w(x, y, t)-\quad$ functions of groundwater levels $(\mathrm{GV})$, infiltration, evaporation from the surface of the ground water level (GWL).

D - area of filtration (AF); G - border of AT; $\mathrm{n}$ - normal to the border of AF. $\tilde{h}_{0}(x, y), \tilde{k}(x, y), \tilde{\gamma}(x, y, t)$ - given fuzzy filtering.

Fuzzy-deterministic model (1) - (3) for specific data defined natural environment is realized through the use of finite difference method [7].

On the base image $\mathrm{HGO} \mathrm{KWGV}$ is constructed information model that provides the link between $\mathrm{HGO}$ and its BAT. At the same time, the structure of the GIS model KWGV includes topological elements point (wells, observation, water intakes), linear (irrigation channels and infiltration), polygonal (guarded zone, recovery) character. Further are formed the base of GIS data, information reflecting the relationship between the biological elements GIS KWGV model (Figure 2). [13]. 


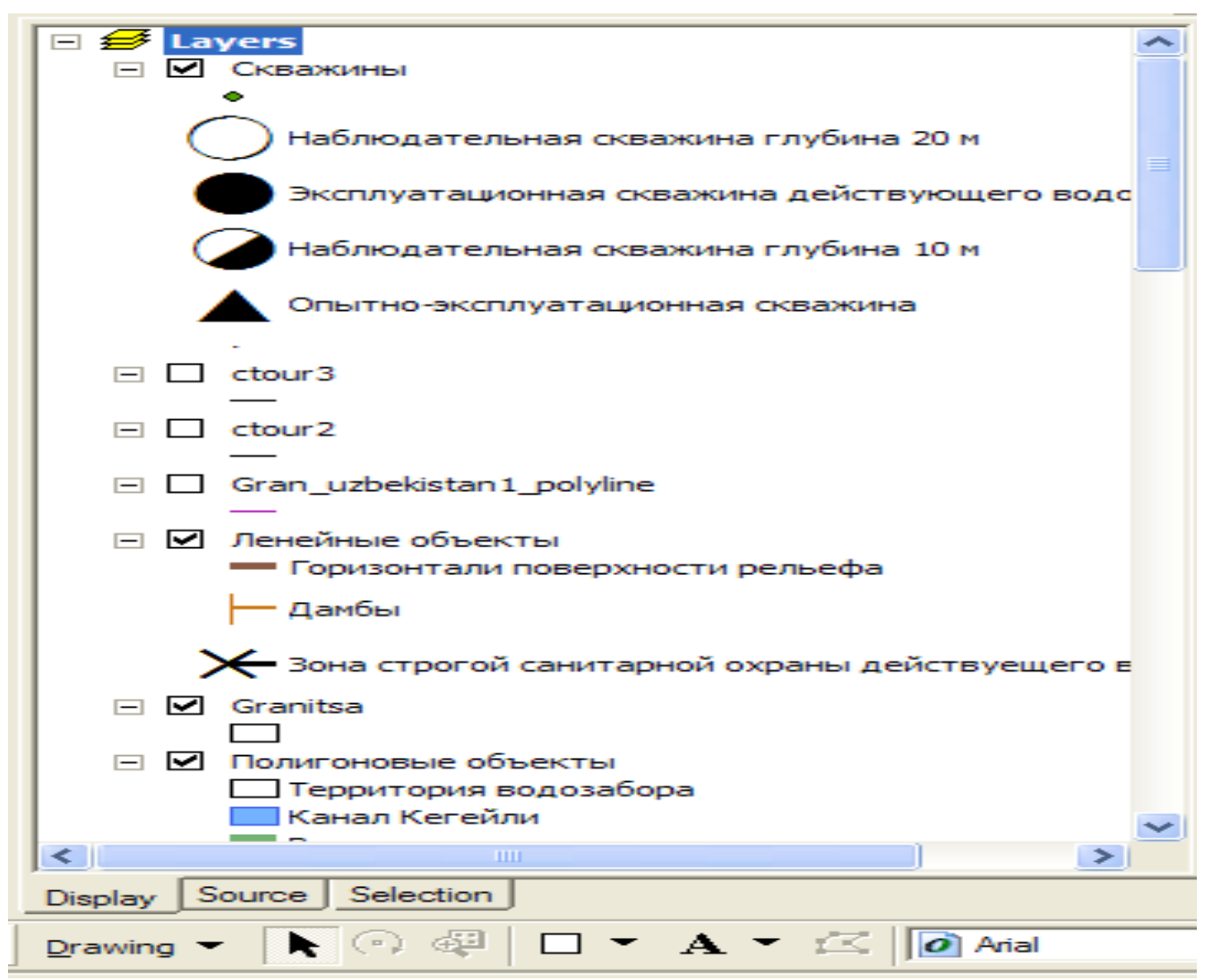

Fig-2: GIS layers model KWGV

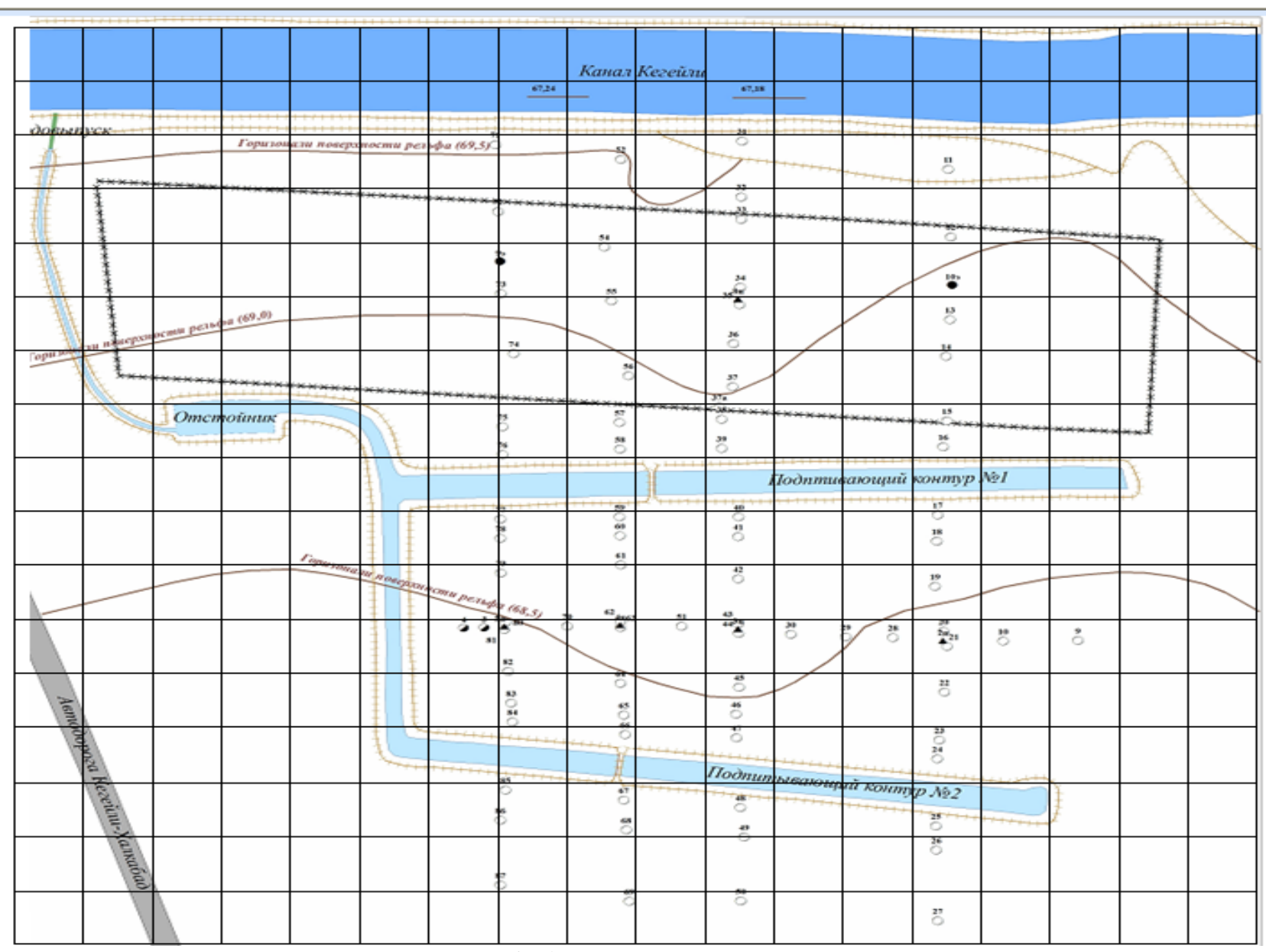

Fig-3: Net model KWGV 
On the basis of the database is constructed information technology model KWGV (Fig. 4.5)

\begin{tabular}{|c|c|c|c|c|c|c|c|c|c|c|c|c|c|c|c|c|c|c|}
\hline 20000 & 10000 & 10000 & 10000 & 10000 & 10000 & 10000 & 10000 & 10000 & 10000 & 10000 & 10000 & 10000 & 10000 & 10000 & 10000 & 10000 & 10000 & 20000 \\
\hline 20000 & 100 & 100 & 100 & 100 & 100 & 100 & 100 & 100 & 100 & 100 & 100 & 100 & 100 & 100 & 100 & 100 & 100 & 20000 \\
\hline 20000 & 300 & 0 & 0 & 0 & 0 & 0 & 0 & 0 & 0 & 0 & 0 & 0 & 0 & 0 & 0 & 0 & 0 & 20000 \\
\hline 20000 & 300 & 0 & 0 & 0 & 0 & 0 & 0 & 0 & 0 & 0 & 0 & 0 & 0 & 0 & 0 & 0 & 0 & 20000 \\
\hline 20000 & 300 & 0 & 0 & 0 & 0 & 0 & 0 & 0 & 0 & 0 & 0 & 0 & 0 & 0 & 0 & 0 & 0 & 20000 \\
\hline 20000 & 300 & 0 & 0 & 0 & 0 & 0 & 0 & 0 & 0 & 0 & 1 & 0 & 0 & 0 & 0 & 0 & 0 & 20000 \\
\hline 20000 & 300 & 0 & 0 & 0 & 0 & 0 & 0 & 0 & 0 & 0 & 0 & 0 & 0 & 0 & 0 & 0 & 0 & 20000 \\
\hline 20000 & 300 & 300 & 300 & 300 & 300 & 0 & 0 & 0 & 0 & 0 & 0 & 0 & 0 & 0 & 0 & 0 & 0 & 20000 \\
\hline 20000 & 0 & 0 & 0 & 0 & 300 & 300 & 300 & 300 & 300 & 300 & 300 & 300 & 300 & 300 & 300 & 300 & 0 & 20000 \\
\hline 20000 & 0 & 0 & 0 & 0 & 300 & 0 & 0 & 0 & 0 & 0 & 0 & 0 & 0 & 0 & 0 & 0 & 0 & 20000 \\
\hline 20000 & 0 & 0 & 0 & 0 & 300 & 0 & 0 & 0 & 0 & 0 & 0 & 0 & 0 & 0 & 0 & 0 & 0 & 20000 \\
\hline 20000 & 10000 & 0 & 0 & 0 & 300 & 0 & 1 & 0 & 1 & 0 & 1 & 0 & 0 & 1 & 0 & 0 & 0 & 20000 \\
\hline 20000 & 10000 & 0 & 0 & 0 & 300 & 0 & 0 & 0 & 0 & 0 & 0 & 0 & 0 & 0 & 0 & 0 & 0 & 20000 \\
\hline 20000 & 10000 & 10000 & 0 & 0 & 300 & 300 & 300 & 0 & 0 & 0 & 0 & 0 & 0 & 0 & 0 & 0 & 0 & 20000 \\
\hline 20000 & 10000 & 10000 & 10000 & 0 & 0 & 0 & 0 & 300 & 300 & 300 & 300 & 300 & 300 & 300 & 300 & 0 & 10000 & 20000 \\
\hline 20000 & 10000 & 10000 & 10000 & 10000 & 10000 & 10000 & 0 & 0 & 0 & 0 & 0 & 0 & 0 & 0 & 0 & 0 & 10000 & 20000 \\
\hline 20000 & 10000 & 10000 & 10000 & 10000 & 10000 & 10000 & 10000 & 0 & 0 & 0 & 0 & 0 & 0 & 0 & 0 & 10000 & 10000 & 20000 \\
\hline
\end{tabular}

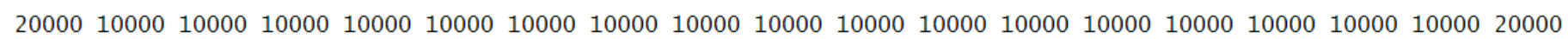

Fig-4: Information technological model KWGV

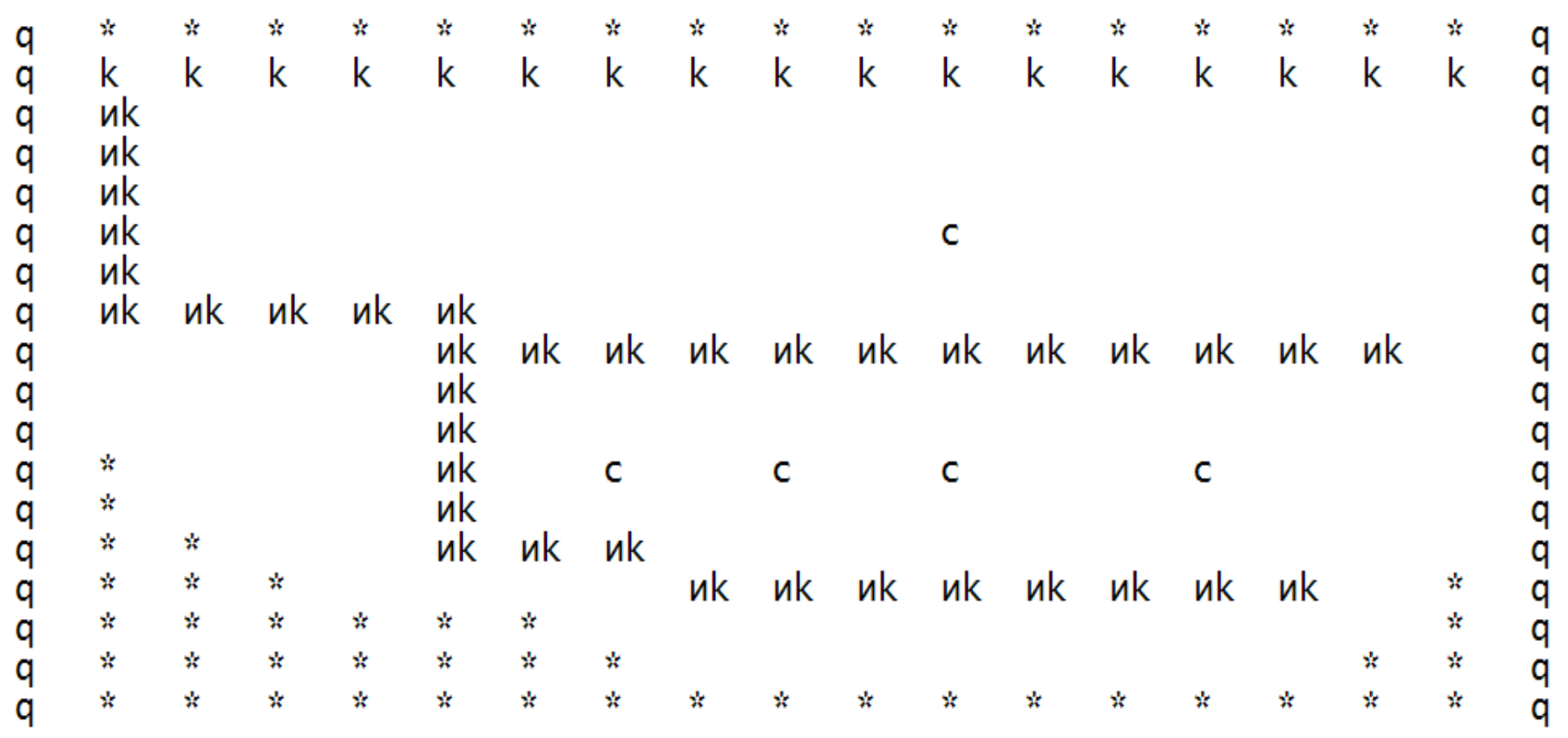

Fig-5: Symbolic representation KWGV in terms of: * - borders AF; uk - infiltration channels; k - channels; c - wells of water intakes

Furthermore is identification of problems are solved on the characterization of the aquifer, the initial and boundary conditions based on fuzzy-deterministic model geofiltration. To do this, in term of aquifer is divided into several zones of inhomogeneous, which is replaced by a grid area. For each node of the grid area is placed appropriate an integer number $\mathrm{i}_{1}, \mathrm{i}_{2}, \mathrm{i}_{3}, \mathrm{i}_{4}, \mathrm{i}_{5}, \mathrm{i}_{6}, \mathrm{i}_{7}$, discharges which are the following: $\mathrm{i}_{1}$-zone number heterogeneity; $\mathrm{i}_{2} \mathrm{i}_{3}$ - type $\mathrm{AF} ; \mathrm{i}_{4} \mathrm{i}_{5}$-the total number of terms that make up the term set of parameters; $\mathrm{i}_{6} \mathrm{i}_{7}$-term number.

In the information model of fuzzy-deterministic definition of the filtration $\tilde{K}=\tilde{K}(x, y)$ coefficient values $\mathrm{i}_{1}, \mathrm{i}_{2} \mathrm{i}_{3}, \mathrm{i}_{4} \mathrm{i}_{5}$ and $\mathrm{i}_{6} \mathrm{i}_{7}$ are formed on the following basis. 
The process of formalizing the fuzzy parameter $\tilde{K}=\tilde{K}(x, y)$ values based on the principles of fuzzy sets theory (FST) on, the example of determining $\tilde{K}=\tilde{K}(x, y)$ the values by constructing membership functions (MF) fuzzy parameter, where $\mathrm{x}, \mathrm{y}$ - the coordinates of AF [1,2].

To formalize fuzzy values of the coefficient of filtration $\tilde{K}=\tilde{K}(x, y)$ used trapezoidal fuzzy numbers $\tilde{K}$ are given by [3]:

$$
\tilde{K}=\left(\underline{K}_{0}, \bar{K}_{0}, \underline{K}_{1}, \bar{K}_{1}\right)
$$

Where $\underline{K}_{0}\left(\bar{K}_{0}\right)$ - the lower (upper) boundary fuzzy number $\tilde{K}$ at zero $\alpha$-level; $\underline{K}_{1}\left(\bar{K}_{1}\right)$ lower (upper) boundary fuzzy number $\tilde{K}$ on the unit $\alpha$-level; Interval $\left\lfloor\underline{K}_{1}, \bar{K}_{1}\right\rfloor$ is called an optimistic estimate of the parameter $\mathrm{K}$, and the interval $\left\lfloor\underline{K}_{0}, \bar{K}_{0}\right\rfloor$ pessimistic assessment of the character of K.

Carrier fuzzy number $\tilde{K}$ is the interval $\left\lfloor\underline{K}_{0}, \bar{K}_{0}\right\rfloor$, and the kernel - $\left\lfloor\underline{K}_{1}, \bar{K}_{1}\right\rfloor$ Go fuzzy number of trapezoidal shape $\tilde{K}=<\underline{K}_{0}, \bar{K}_{0}, \underline{K}_{1}, \bar{K}_{1}>$ to $\alpha-$ leveled description, that means, $\tilde{q}=\bigcup_{a \in[0,1]}\left(\underline{K}_{a}, \bar{K}_{a}\right)$ carried out by the formulas:

$$
\begin{aligned}
& \underline{K}_{a}=\underline{K}_{0}+\left(\underline{K}_{1}-\underline{K}_{0}\right) a \\
& \bar{K}_{a}=\bar{K}_{0}-\left(\bar{K}_{0}-\bar{K}_{1}\right)
\end{aligned}
$$

Next, proceed to the linguistic $-l$ form $\tilde{K}$

$l$ - a form of uncertain parameter $\tilde{K}$ is a triple $[1,6]$

$$
K=(\underline{K}, \bar{K}, l),
$$

where $\underline{K}(\bar{K})$ - the lower (upper) boundary changing of the parameter $\mathrm{K}$ :

$l$ - a linguistic estimate of the parameter $\mathrm{K}$ in the range $\lfloor\underline{K}, \bar{K}\rfloor$, and $l \in L=\left\{l_{1}, l_{2}, \ldots ., l_{m}\right\} . L$ - linear - set of linguistic terms ordered according to the principle of "less" to "large". Further on information model is designed AF, whose main objective is to establish the relationship between the object and its hydrogeological numerical model, as well as the organization of computational experiments (CEs) in order to ensure the possibility of varying the different boundary conditions in the numerical simulation.
Further information model designed PF, whose main objective - to establish the relationship between the object and its hydrogeological numerical model, as well as the organization of computational experiments (CEs) [8,9] in order to ensure the possibility of varying the different boundary conditions in the numerical simulation. This software is aimed to study hydro facilities, both local and regional scale using data of different nature:

- numerical data character (the values of groundwater levels, the parameters of aquifers, wells costs, etc.);

- linguistic data (experience, knowledge, opinions of experts (hydrogeologists, hydrologists, irrigators, land reclamation, etc. have sufficient experience with the considered HGO));

- Data received by means of digital image processing HGO.

Carrying of $\mathrm{CE}$ on renewable energy evaluation of different parameters and factors on underground hydrosphere KWGV carried fuzzy-deterministic method based on GIS:

- First, on the basis of BAT geofiltration are conducted experiments to determine the initial and boundary conditions, fuzzy distribution of geofiltration parameters on the basis of GIS, which is visualized by Surfer (Fig.8,9)

- GIS-based model KWGV are conducted experiments to assess the impact modeformed and anthropogenic factors on the main aquifer, the results of which are visualized in the medium Arc Map

- Based on a comparison of the results of CE obtained RE BAT and GIS-based decision-making on the selection and justification of the mode of formation and operation KWGV.

BAT KWGV is based on the information model of underground hydrosphere shown in Fig.1. AF replaced by the grid area with 19 rows and 18 columns, with a spacing of $100 \mathrm{~m} \mathrm{[10].}$

In the following order:

1. The structure of NDM KWGV GIS basis.

2. Construction of information technology SVC model (Fig.1.).

3. Construction of information model to determine the filter coefficients on the basis of fuzzy-deterministic (Fig.2.).

4. Identification of the filter coefficients based on the solution of the inverse problem using the results 2 . 
1010501101050210105032010504101050520105012010502201050320105022010503301050130105023010503301050530105013010502301050330105052010504 1010501101050220105031010504201050120105022010503201050330105013010502301050230105033010502301050130105023010502301050330105021010504 1010501201050220105012010502201050320105043010501201050230105023010503301050430105023010501201050230105023010503301050430105022010502 1010501201050220105012010502301050130105022010503301050430105043010505301050530105022010503301050430105043010505301050530105022010502 1010501101050220105031010504101050520105012010502201050320105033010504301050430105053010505301050230105013010502301050330105021010504 1010501101050210105032010504201050120105022010503301050120105033010504301050430105053010505301050230105023010502301050330105012010504 1010501101050220105012010502201050320105043010501301050220105033010504301050430105053010505301050230105023010503301050430105012010502 1010501101050210105032010504201050120105022010503301050120105033010504301050430105053010505301050230105023010502301050330105012010504 1010501101050220105012010502201050320105043010501301050220105033010504301050430105053010505301050230105023010503301050430105012010502 1010501101050220105012010502201050320105043010501301050220105033010504301050430105053010505301050230105023010503301050430105012010502 1010501101050210105032010504201050120105022010503301050120105033010504301050430105053010505301050230105023010502301050330105012010504 1010501201050220105012010502201050320105043010501201050230105023010503301050430105023010501201050230105023010503301050430105022010502 1010501101050210105032010504201050120105022010503301050120105033010504301050430105053010505301050230105023010502301050330105012010504 1010501201050220105012010502201050320105043010501201050230105023010503301050430105023010501201050230105023010503301050430105022010502 1010501101050210105032010504201050120105022010503301050120105033010504301050430105053010505301050230105023010502301050330105012010504 1010501201050220105012010502201050320105043010501201050230105023010503301050430105023010501201050230105023010503301050430105022010502 1010501101050210105032010504201050120105022010503301050120105033010504301050430105053010505301050230105023010502301050330105012010504 1010501201050220105012010502201050320105043010501201050230105023010503301050430105023010501201050230105023010503301050430105022010502

Fig-6: The Information model for the representation of the coefficients on the basis of BAT.

\begin{tabular}{|c|c|c|c|c|c|c|c|c|c|c|c|c|c|c|c|c|c|c|}
\hline 67.18 & 67.18 & 67.18 & 67.18 & 67.18 & 67.18 & 67.18 & 67.18 & 67.18 & 67.18 & 67.18 & 67.18 & 67.18 & 67.18 & 67.18 & 67.18 & 67.18 & 67.18 & 67.18 \\
\hline 67.18 & 67.18 & 67.18 & 67.18 & 67.18 & 67.18 & 67.18 & 67.18 & 67.18 & 67.18 & 67.18 & 67.18 & 67.18 & 67.18 & 67.18 & 67.18 & 67.18 & 67.18 & 67.18 \\
\hline 67.00 & 67.00 & 67.00 & 67.00 & 67.00 & 67.00 & 67.00 & 67.00 & 67.00 & 67.00 & 67.00 & 67.00 & 67.00 & 67.00 & 67.00 & 67.00 & 67.00 & 67.00 & 67.00 \\
\hline 67.50 & 67.50 & 67.00 & 67.00 & 67.00 & 67.00 & 67.00 & 67.00 & 67.00 & 67.00 & 67.00 & 67.00 & 67.00 & 67.00 & 67.00 & 67.00 & 67.00 & 67.00 & 67.00 \\
\hline 57.50 & 67.50 & 67.50 & 67.00 & 67.00 & 67.00 & 67.00 & 67.00 & 67.00 & 67.00 & 67.00 & 67.00 & 67.00 & 67.00 & 67.00 & 67.00 & 67.00 & 67.00 & 67.00 \\
\hline 68.00 & 68.00 & 67.50 & 67.50 & 67.50 & 67.00 & 67.00 & 67.00 & 67.00 & 67.00 & 67.00 & 67.00 & 67.00 & 67.00 & 67.00 & 67.00 & 67.00 & 67.50 & 67.50 \\
\hline 7.50 & 68.00 & 68.00 & 68.50 & 67.50 & 67.00 & 67.00 & 67.00 & 67.00 & 67.00 & 67.00 & 67.00 & 67.00 & 67.00 & 67.00 & 67.00 & 67.50 & 67.50 & 67.50 \\
\hline 67.50 & 68.00 & 68.00 & 68.00 & 68.00 & 68.00 & 67.50 & 67.50 & 67.50 & 67.50 & 67.50 & 67.50 & 67.50 & 67.50 & 67.50 & 67.50 & 67.50 & 67.50 & 67.50 \\
\hline 7.50 & 67.50 & 67.50 & 68.00 & 68.00 & 68.00 & 68.00 & 68.00 & 68.00 & 68.00 & 68.00 & 68.00 & 68.00 & 68.00 & 68.00 & 68.00 & 68.00 & 67.50 & 67.50 \\
\hline 57.50 & 67.50 & 67.50 & 67.50 & 67.50 & 68.00 & 68.00 & 68.00 & 68.00 & 68.00 & 68.00 & 68.00 & 68.00 & 68.00 & 68.00 & 68.00 & 68.00 & 67.50 & 67.50 \\
\hline 57.50 & 67.50 & 67.50 & 67.50 & 67.50 & 68.00 & 67.50 & 67.00 & 67.00 & 67.00 & 66.50 & 66.50 & 67.00 & 66.50 & 66.50 & 67.00 & 67.50 & 67.50 & 67.50 \\
\hline 57.50 & 67.50 & 67.50 & 67.50 & 68.00 & 68.00 & 67.00 & 66.00 & 66.00 & 66.50 & 66.00 & 66.00 & 66.50 & 66.00 & 66.00 & 66.50 & 67.00 & 67.50 & 67.50 \\
\hline 67.50 & 67.50 & 67.50 & 67.50 & 67.50 & 68.00 & 67.50 & 66.50 & 66.50 & 66.50 & 66.00 & 66.50 & 66.50 & 66.50 & 66.50 & 67.00 & 67.50 & 67.50 & 67.50 \\
\hline 67.50 & 67.50 & 67.50 & 67.50 & 67.50 & 68.00 & 67.50 & 67.50 & 67.50 & 67.50 & 67.00 & 67.00 & 67.50 & 67.00 & 67.00 & 67.00 & 67.50 & 67.50 & 67.50 \\
\hline 77.50 & 67.50 & 67.50 & 67.50 & 67.50 & 68.00 & 68.00 & 68.00 & 68.00 & 68.00 & 68.00 & 68.00 & 68.00 & 68.00 & 68.00 & 68.00 & 67.50 & 67.50 & 67.50 \\
\hline 67.50 & 67.50 & 67.50 & 67.50 & 67.50 & 67.50 & 67.50 & 67.50 & 67.00 & 67.00 & 67.00 & 67.00 & 67.50 & 67.50 & 68.50 & 68.50 & 67.50 & 67.50 & 67.50 \\
\hline 67.50 & 67.50 & 67.50 & 67.50 & 67.50 & 67.50 & 67.00 & 67.00 & 67.00 & 67.00 & 67.00 & 67.00 & 67.00 & 67.00 & 67.00 & 67.00 & 67.00 & 67.00 & 67.50 \\
\hline 57.00 & 67.00 & 67.00 & 67.00 & 67.00 & 67.00 & 67.00 & 67.00 & 67.00 & 67.00 & 67.00 & 67.00 & 67.00 & 67.00 & 67.00 & 67.00 & 67.00 & 67.00 & 67.00 \\
\hline
\end{tabular}

Fig-7: Distribution of GWL KWGV obtained in fuzzy-based deterministic 


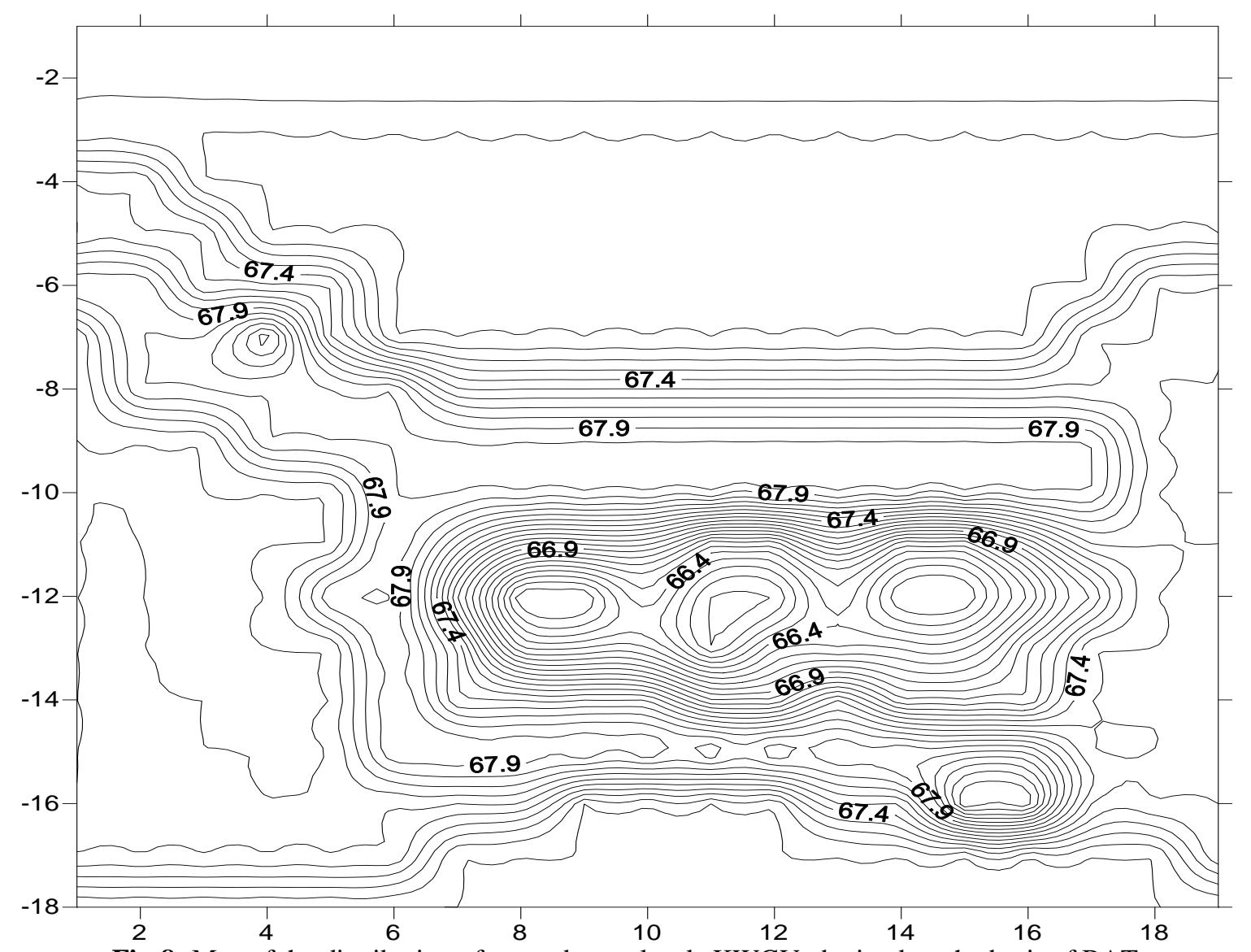

Fig-8: Map of the distribution of groundwater levels KWGV obtained on the basis of BAT

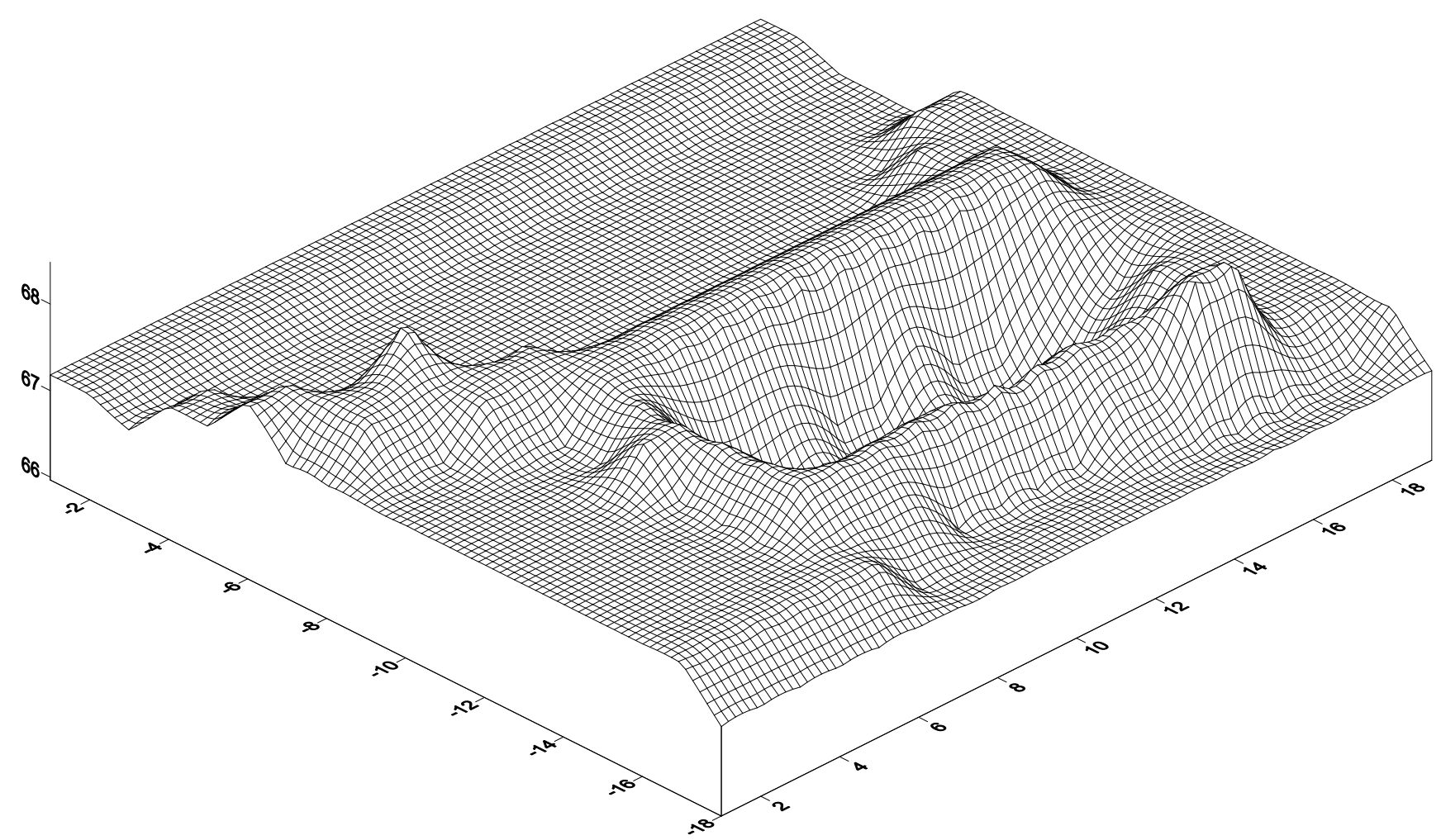

Fig-9: Visualization of results RE in bulk form KWGV. 
The results of computational experiments to validate process diagrams, charts changes KWGV modes for specific cuts, presented in table-1.

Table-1: Graphical representation of typical sections

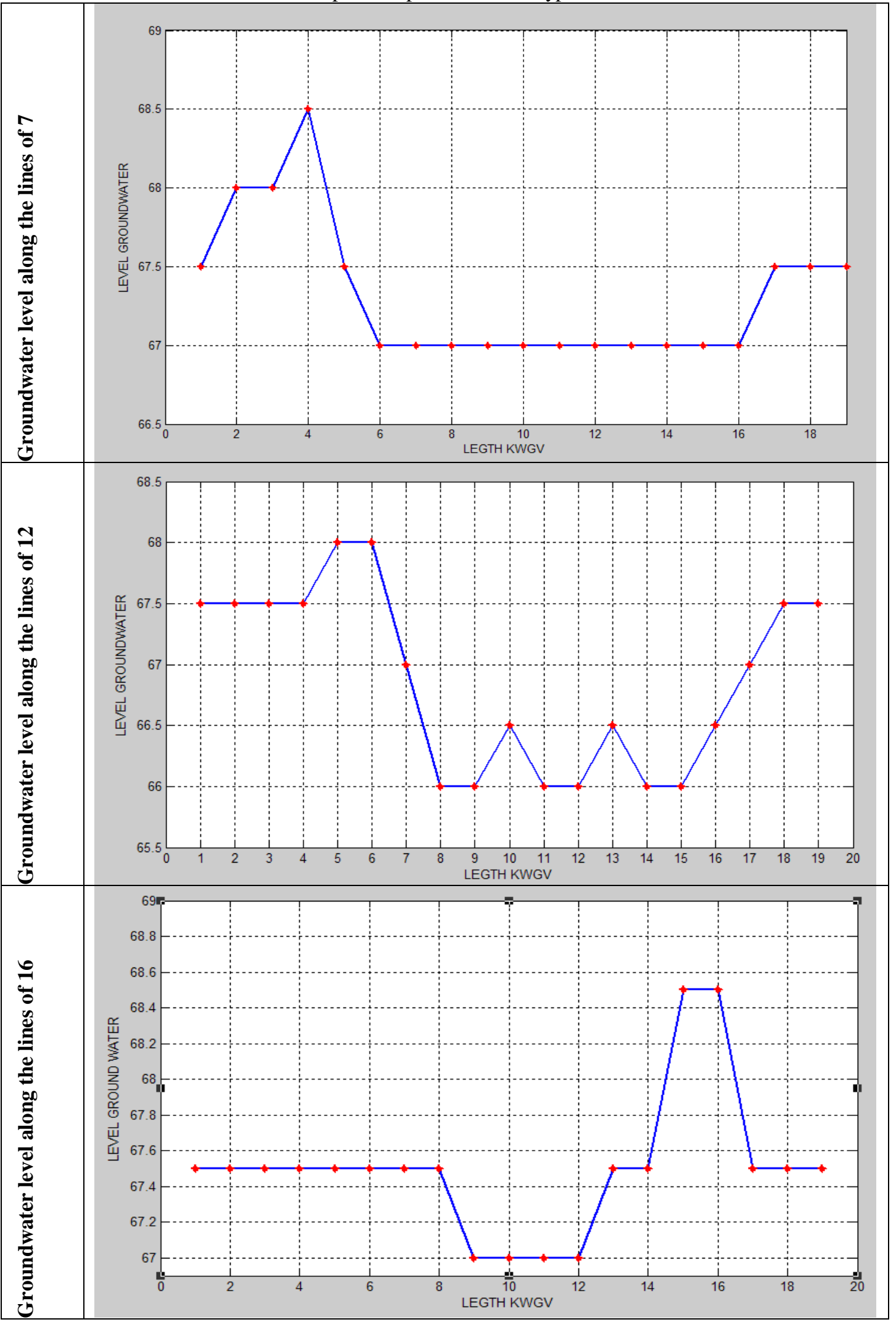

As the distance from the alignment of a number of wells, a decrease in water intake and stabilize groundwater levels. (Fig. 8.9 and Table-1) 


\section{CONCLUSION}

1. Are proposed scientific and methodological bases of integration of GIS technologies fuzzy-deterministic simulation geofiltration processes in single layers, information technology modeling KWGV providing the relationship between the object KWGV and its fuzzy-deterministic model.

2. Formalizations of fuzzy parameter $\tilde{K}=\tilde{K}(x, y)$ is based on the principles of FST to allow submission of a fuzzy linguistic values of the parameter $\tilde{K}=\tilde{K}(x, y)$ in the form of fuzzy numbers (triangular, trapezoidal).

3. Algorithms of formation of information-technology model KWGV information model of the filtering process in an inhomogeneous in terms of PF allow you to organize the relationship between $\mathrm{KWGV}$ and fuzzy-deterministic model RP, RE organize in order to substantiate the various parameters and boundary conditions.

\section{REFERENCES}

[1] O. Kaleva. Fuzzy differential equations. Fuzzy Sets and Systems, 24(1987), 301-307/

[2] O. Kaleva. The Cauchy problem for fuzzy differential equations. Fuzzy sets and systems, 35 (1990), 389396pp.

[3] O.Fazajzadeh. An Explicit Method for Soling Fuzzy Partial Differention Equation. International Mathematical Forum,5,2010,№21,1025-1036pp.

[4] Rothstein AP, Loikaw EE, Katelnikov DI. Predicting the number of diseases on the basis of expert and linguistic information // Cybernetics and Systems Analysis. -1999.-№2. - pp.178-185.

[5] Altunin A.E., Semukhin M.V. Models and algorithms for decision making in fuzzy environment. - Tyumen: Publishing House of the Tyumen State University, 2000. - 352pp.

[6] Samarskiy A.A., Mikhailov A.P., Mathematical modeling: the Ideas. Methods. Examples. 2nd ed., Ispr.i M .: FIZMATLIT, 2005.-300pp.-ISBN 5-922101-20-X.

[7] Samarskiy A.A., Frazinov I.V. Difference approximation methods for problems of mathematical physics // UMN.-Moscow, 1976.-T.31.-pp.167-197.

[8] Usmanov R.N. On the question of the numerical simulation of the formation and operation of groundwater is abstracted in a fuzzy information // Bulletin Tash GTU. - Tashkent, 2006 - №2.- pp.3-6.

[9] Usmanov R.N. Fuzzy modeling of processes in water intake systems of artificial groundwater recharge // Chemical technology. Control and management. Tashkent, 2007. - № 1.-pp. 63-69.

[10] Usmanov R.N., Djumanov Zh.Kh., Seitnazarov K.K., Oteniyazov R.I. Software package for information and numerical modeling geofiltration processes in single layers // Certificate of Deposit of intellectual property number 1723 from 12.02.2014.
[11] Konoplyev A.V., Krasil'nikov P.A., Krasil'nikova S.A., Klëtskina O.V. Kartosemioticheskaya geographic information model as the basis for creating a hydrodynamic model // Scientific Journal KubGAU, №84 (10), 2012

[12] Konoplyev A.V., Krasil'nikov P.A. Gioinformatsionnoe natural resources mapping Perm Krai // Collection of scientific works. Issue 2 PGU.Perm.-2009-pp.30-39.

[13] Glotov A.A., Mikhno V.B. Gioinformatsionnoe modeling of river valleys and forest-steppe landscapes of Central // Herald of the Voronezh State University, Series: Geography. Gioekologiya, №1.Russia, 2013-pp47-52.

\section{BIOGRAPHY}

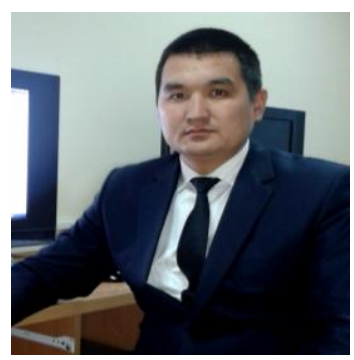

Seitnazarov Kuanyshbaev Kenesbaevich - assistant of the Department "Computer Systems", Tashkent University of Information Technologies. 